Volume: 11 Issue: 2 Year: 2014

\section{The adaptation of Flow Short Scale to Turkish: A validity and reliability study}

\section{Flow Yaşantısı Ölçeği Kısa Formunun Türkçeye uyarlama, geçerlik ve güvenirlik çalışması}

\author{
Bahar İşigüzel $^{1}$ \\ Sabahattin Çam ${ }^{2}$
}

Özet

Bu çalısmanın amac1, Rheinberg, Vollmeyer ve Engeser (2003) tarafindan geliştirilen Flow Yaşantısı Ölçeği Kısa Formu'nun (Flow Kurz Skala) Türkçeye uyarlama, geçerlik ve güvenirlik çalışmasını yapmaktır. Araştırmaya 124'ü kadın, 98'i erkek toplam 222 yabancı dil hazırlık sınıfı üniversite öğrencisi katılmıştır. Ölçeğin geçerliğine yapı geçerliği ve ölçüt bağlantılı geçerlik yaklaşımlarıla bakılmıştır. Aracın güvenirliği ise iç tutarlık katsayısı hesaplanarak incelenmiştir. Ölçeğin basit ve kararlı bir yapıya sahip olup olmadığını anlamak için Açılayıcı Faktör Analizi uygulanmiştır. Analiz sonucunda, maddelerin ölçeğin orijinaline benzer şekilde flow ve kayg1 yaşantısı boyutlarına yüklendiği görülmüsstür. Aracın ölçüt bağıntılı geçerliliğini sınamak amaciyla, ölçek puanları cinsiyete göre karşılaşturılmış ve dönem sonu yabancı dil başarı puanları ile ölçek puanları arasındaki ilişkilere bakılmıştır. Sonuçta ölçek puanlarının cinsiyete göre farklılaşmadığı görülmekle birlikte, yabancı dil başarı puanlarının flow yaşantusı ile pozitif yünde ( $\mathrm{r}=.21)$ ve kayg1 ile negatif yönde ( $r=.34)$ düşük düzeyde anlamlı ilişkileri olduğu bulunmuştur. Ölçek maddelerinin tümüne ilişkin iç tutarlık

${ }^{1}$ Yrd. Doç. Dr., Nevşehir Hacı Bektaş Veli Üniversitesi, Eğitim Fakültesi, Yabancı Diller Eğitimi Bölümü, bahar.isiguzel@nevsehir.edu.tr

${ }^{2}$ Yrd. Doç. Dr., Çukurova Üniversitesi, Eğitim Fakültesi, Eğitim Bilimleri Bölümü, sabahcam@,cu.edu.tr 
İşigüzel, B., \& Çam, S. (2014). Flow Yaşantısı Ölçeği Kısa Formunun Türkçeye uyarlama, geçerlik ve güvenirlik çalışmasi. International Journal of Human Sciences, 11(2), 788-801. doi: 10.14687/ijhs.v11i2.2826

measuring university students' Flow katsayısı .78, flow yaşantısı puanları için .88 ve Experiences by the foreign language lessons kayg1 puanları için de .67 olduğu in prep- classes.

hesaplanmıştır. Bulgular, uyarlaması yapılan Flow Yaşantısı Ölçeği Kısa Formu'nun Türk

Keywords: Flow short scale, adaptation, validity, reliability, foreign language achievievement.

kültüründe yabanc1 dil öğrenen üniversite öğrencilerinin öğrenme sürecindeki flow yaşantılarını ölçmek için kullanılabilecek bir araç olduğunu göstermektedir.

(Extended English abstract is at the end of this document)

Anahtar Sözcükler: Flow Yaşantısı Ölçeği, uyarlama, geçerlik, güvenirlik, yabancı dil başarısı.

\section{Giriş}

Öğrenmenin bilişsel- güdüsel süreç modeline göre öğrenme başarısının üç süreç Özelliğine bağlıdır (Rheinberg, Vollmeyer ve Rollett, 2000; Vollmeyer ve Rheinberg, 1998; Engeser, vd., 2005). Bunlar;

- Aktif öğrenme süresi,

- Öğrenme aktivitelerinin niteliği ve kalitesi,

- Öğrenen kişinin öğrenme sürecindeki fonksiyonel durumu.

$\mathrm{Bu}$ modele göre bireyin aktif öğrenme süresi, öğrenme sürecinin ayrllmaz bir parçası olarak kabul edilmektedir (Fraser ve Walberg, 1991; Engeser, vd. 2005). Aktif öğrenme süresi, öğrenen kişinin bilinçli olarak ders aktivitelerine katılım sağlaması ve öğrenmek için gayret etmesidir. İkinci özellik olan öğrenme süreçlerinde öğrenme aktivitelerinin niteliği ve kalitesi de içsel güdülenme üzerinde etkiler göstererek başarıyı olumlu etkilemektedir (Vollmeyer ve Rheinberg, 1998). Üçüncü boyut olan öğrenen kişinin öğrenme süreci esnasındaki fonksiyonel durum, kişinin öğrenme süreci devam ederken içinde bulunduğu duyuşsal durumdur. Bu bağlamda fonksiyonel durum duyuşsal bir faktör olarak içsel motivasyonla kesişmektedir. İçsel güdülenme yaşayan kişi için o an yaptığı aktivite başlı başına bir içsel motivasyon kaynağıdır. Kişi dış kaynaklar tarafından bir ödüllendirilmeye ihtiyaç duymamaktadır ve kendi hedeflerini kendisi belirleyip, kendi içsel gücünü ve aktivitedeki kendi potansiyelini ödül olarak ortaya çıkarabilmektedir (Deci, 1975; Apelt ve Krück 1980; Deci ve Ryan, 1985; Kleppin 2001). İçsel motivasyon araştırmaları ile kişilerin aktiviteleri sürdürürken içsel bir flow yaşantısı durumuna ulaştıkları ortaya atılmıştır (Martin, 2000). Flow kavramının Türkçede karşıllğı tam olarak bulunmamakla birlikte bu kavramın Türkçe karşılıkları akış, akış hali, yaşantı akışı olarak aktarılabilir. Flow yaşantısı, bireylerin bir aktivite esnasında içinde bulunduğu ana odaklanarak içsel motivasyonunda etkisiyle enerjik, keyifli, pozitif, kendine güvenen, bedensel rahatliğın yaşandığı ve kendi içinde ödüllendirici bir varoluş olarak tanımlanmıştır (Loehr, 1986). 
İşigüzel, B., \& Çam, S. (2014). Flow Yaşantısı Ölçeği Kısa Formunun Türkçeye uyarlama, geçerlik ve güvenirlik çalışmasi. International Journal of Human Sciences, 11(2), 788-801. doi: 10.14687/ijhs.v11i2.2826

Csikszentmihalyi $(1988$; 1990) flow teorisinde, kişilerin içsel motivasyon ve flow yaşantısı deneyimi ile dış kaynaklı ödüllendirmeler olmaksızın yaptıklanı eylem anında daha yüksek performanslara eriştiklerini belirtmektedir. Bir aktivite anında kişilerin flow yaşantı durumunu ortaya çıkaran belli bileşenler vardır. Bu bileşenler aşağıdaki şemada gösterilmiştir:

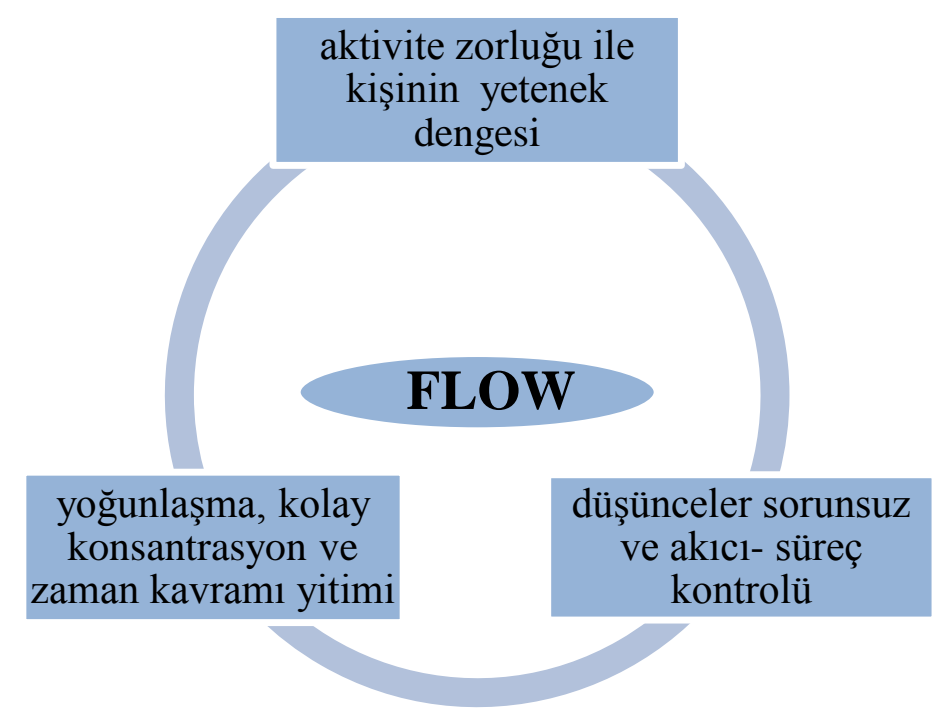

Şema 1. Flow Yaşantısı Bileşenleri

Şemaya göre flow yaşantısı süreci bu şekilde oluşmaktadır:

- Aktivitenin zorluk derecesi ile kişinin yetenek seviyesi arasında bir denge olmalıdır.

Kişi aktivite esnasinda aktivitenin zorluk derecesinin kendi seviyesine uygun olduğunu düşünmelidir.

- Kişi aktivite esnasında aktivite hakkındaki düşüncelerinin sorunsuz ve akıcı olduğunu düşünmelidir. Aktivitenin içeriği ile ilgili kişinin kafasında soru işareti olmamalı ve her adımda tam olarak ne yapması gerektiğini bildiğini ve tüm aktivite sürecini kontrol altında tuttuğunu düşünmelidir.

- Kişi tamamen yoğunlaşarak, aktiviteye kendini tamamen kaptırmış durumda olmakta, aktivite esnasında dikkatini toplamakta zorluk çekmemektedir ve aktiviteye yoğunlaşma nedeniyle zamanın nasıl geçtiğini anlamamaktadır.

Bu bileşenlerin bir aktivite anında kişinin iç dünyasında oluşması kişinin flow yaşantısı durumuna eriştiğini göstermektedir. Bu bileşenlerin kombinasyonu kişide derin bir mutluluk hissi yaratıp, aktivite için tüm enerjisini bu aktivitedeki flow yaşantısını sürdürmek için kullanma isteği ile sonuçlanmaktadır. Flow yaşantısının yaşanamadığı aksi durumda ise, aktivite ile ilişkili kaygı ortaya çıkmaktadır. Bu bağlamda, kişiler aktivite esnasında aktivite sonucundaki 
İşigüzel, B., \& Çam, S. (2014). Flow Yaşantısı Ölçeği Kısa Formunun Türkçeye uyarlama, geçerlik ve güvenirlik çalışmasi. International Journal of Human Sciences, 11(2), 788-801. doi: 10.14687/ijhs.v11i2.2826

başarıları konusunda olumsuz duygular yaşamaktadırlar. Başarısız olacaklarını, hata yapabileceklerini aktivite boyunca düşünüp, başarısızlığı peşinen kabul etmiş olmaktadırlar (Csikszentmihalyi 1975; Rheinberg, Vollmeyer ve Rolett, 2000; Rheinberg 2002; Engeser, vd. 2005).

Yapılan tarama sonucunda Türkiye'de flow yaşantısını ölçmeyi hedefleyen sadece bir aracın uyarlandığı belirlenmiştir. Bu uyarlama sonucunda "perception questionnaire" olarak Alperer (2005) tarafindan Türkçeye kazandırıldığı belirlenmiştir. Uyarlanan orijinal ölçek, Webster, Trevino ve Ryan'nın (1993) (Flow in computer-mediated communication) bilgisayar ve medya ortamlarındaki flow yaşantıları için geliştirilmiştir. Söz konusu ölçeği ilk olarak Egbert (2003) eğitim ortamları için orijinal ölçeğe iki ek madde ekleyerek uyarlamıştır. Orijinalinde İngilizce olan ölçek 7’li likert yanıt seçenekleri olan 14 madde ve dört boyuttan (değişim, dikkat, ilgi ve kontrol) oluşmaktadır. Bu ölçek Alperer (2005) tarafindan üniversite öğrencileriyle yapılan bir çalışmada Türkçeye uyarlanmıştır. Mühendislik lisans programı öğrencilerinden oluşan İngilizce hazırlık sınıfı örneklemiyle $(\mathrm{N}=26)$ yapılan uyarlama çalışmasında ölçeğin Cronbach Alfa değerinin .93 olduğu görülmüştür. Ancak faktör analizi sonucunda, uyarlanan ölçeğin faktör yapısının özgün ölçek ile tutarlı olmayan ve üç faktörlü (ilgi, dikkat ve kontrol) bir yap1 gösterdiği sonucuna ulaşılmıştır. Ölçeğin sadece kontrol boyutunda üç madde ile orijinal ölçekle örtüştüğü ve diğer 11 maddenin ilgi ve dikkat boyutlarında toplandığı, orijinal ölçekteki değişim boyutu maddelerinin içerik açısından kuramsal olarak ilişkili olmamakla birlikte istatistiksel olarak bu iki boyuta yüklendiği saptanmıştır. Ayrıca flow yaşantısının ölçülmesi işleminde yapılan aktivite esnasında desin içeriğine yoğunlaşıldığı bir süreçte dersin kesilerek ölçülmesi gerekmektedir (Csikszentmihalyi ve Larson, 1987; Csikszentmihalyi ve Csikszentmihalyi, 1991; Rheinberg ve Vollmeyer, 2001). Ancak bu çalışmadaki veri toplama süreci ders aktivitesinin bitiminde flow yaşantısı ölçümü yapılması ve örneklemdeki öğrenci sayısının oldukça az olması $(\mathrm{N}=26)$ uyarlanan ölçeğin kullanılmasının sınırlılıklarını ortaya koymaktadır.

Diğer ölçek ise, Rheinberg, Vollmeyer ve Engeser (2003) tarafindan geliştirilen ve özgün dili Almanca olan Flow Yaşantısı Ölçeği Kısa Formu’dur (Die Flow Kurz Skala). Ölçek flow ve kayg1 yaşantısı olmak üzere iki boyuttan oluşmakta ve eğitim ortamında flow yaşantısını ölçmeyi hedeflemektedir (Ölçekle ilgili geniş bilgi çalışmanın yöntem bölümünde verilmiştir.) Türkçe litaretür incelendiğinde flow yaşantısını ölçebilecek Alperer (2005) tarafindan uyarlanan ve yukarıda sınırlıkları belirtilen başka bir ölçme aracının olmadığı görülmektedir. Böylece öğrenme yaşantısında önemli bir içsel motivasyon boyutu olan flow yaşantısını ölçebilecek bir aracın Türkçe’ye uyarlanması önemli görülmektedir. Dolayısıyla Flow Yaşantısı Ölçeği Kısa 
İşigüzel, B., \& Çam, S. (2014). Flow Yaşantısı Ölçeği Kısa Formunun Türkçeye uyarlama, geçerlik ve güvenirlik çalışmasi. International Journal of Human Sciences, 11(2), 788-801. doi: 10.14687/ijhs.v11i2.2826

Formu'nun (Rheinberg, Vollmeyer ve Engeser, 2003) uyarlanmasının alandaki bu eksikliği gidermede katkı sağlayacağı kabul edilmiştir. Bu ölçeğin uyarlanmasını önemli kılan bir diğer faktör de, psikoloji alanında özellikle Csikszentmihalyi (1975) tarafından önerilen tüm flow bileşenlerini kapsaması ve yabancı dil derslerinde hedeflenen içsel motivasyon yapısıyla kesişmesidir. Böylece çalışmada, Flow Yaşantısı Ölçeği Kısa Formu’nun yabancı dil derslerinde Türk öğrencilerinin flow yaşantısı düzeylerini ölçebilecek nitelikte olup olmadığının belirlenmesi amaçlanmıştır. Bu bağlamda, orijinal ölçeğin faktör yapısı, ölçüt bağıntılı geçerlik ve güvenirliği ile ilgili psikometrik özellikleri incelenmiştir.

\section{Yöntem}

\section{Araştırma Grubu}

Araştırmanın çalışma evrenini, Nevşehir Hacı Bektaş Veli Üniversitesi Yabancı Diller Bölümü bünyesinde İngilizce hazırlı sınıfina kayıtlı toplam 600 üniversite öğrencisi oluşturmaktadır. Örnekleme 2013-2014 eğitim - öğretim yılında Nevşehir Hacı Bektaş Veli Üniversitesi Yabanc1 Diller Bölümünde İşletme, İktisat, Kamu Yönetimi ve Turizm İşletmeciliği ve Otelcilik bölümlerinin İngilizce hazırlık sınıfına devam eden toplam 222 öğrenci katılmıştır. Çalışma grubunda yer alan öğrencilerin cinsiyet, yaş ve kayıtlı oldukları bölümlere ilişkin dağılımları Tablo 1'de sunulmuştur.

Tablo 1. Çalışma Grubunun Özellikleri

\begin{tabular}{lll}
\hline & $\mathbf{N}$ & $\mathbf{0}$ \\
\hline Cinsiyet & & \\
Kadın & 124 & 56.0 \\
Erkek & 98 & 44.0 \\
\hline Yaş & & \\
$17-19$ & 179 & 81.0 \\
$20-24$ & 43 & 19.0 \\
\hline Bölüm & & \\
İșletme & 59 & 27.0 \\
İktisat & 55 & 25.0 \\
Kamu Yönetimi & 53 & 23.0 \\
Turizm İşletmeciliği ve Otelcilik & 55 & 25.0 \\
\hline Toplam & $\mathbf{2 2 2}$ & $\mathbf{1 0 0 . 0}$ \\
\hline
\end{tabular}

Çalışma grubunun özellikleri incelendiğinde, grubun \% 56'sının kadın ve \% 44'nün erkek olduğu gözlenmektedir. Öğrencilerin yaşlarının 17 ile 24 arasında değiştiği $(\bar{X}=19.52$; ss= 1.46), \%81'inin 17-19 ve \% 19’unun da 20-24 yaş aralığında oldukları görülmektedir. Bölümlere göre dağılıma bakıldığında katılımcıların \% 27’sinin İşletme; \% 25’inin İktisat, \% 
İşigüzel, B., \& Çam, S. (2014). Flow Yaşantısı Ölçeği Kısa Formunun Türkçeye uyarlama, geçerlik ve güvenirlik çalışması. International Journal of Human Sciences, 11(2), 788-801. doi: 10.14687/ijhs.v11i2.2826

23’ünün Kamu Yönetimi ve \% 25’inin Turizm İşletmeciliği ve Otelcilik bölümlerinde kayttlı oldukları belirlenmiştir.

\section{Orijinal Ölçme Aracı: Flow Yaşantısı Ölçeği Kısa Formu (Flow Kurz Skala)}

Ölçek 7’li likert tipi yanıt seçenkleri olan toplam 13 madde ve iki boyuttan oluşmaktadır. Verilen yanıtların puanlanmasında $(1=$ Hiç Katılmıyorum, $2=$ Katılmıorum, $3=$ Kısmen Katılmıorum, 4= Kararsızım, 5= Kısmen Katıllyorum, 6= Çoğunlukla Katıllyorum, 7= Tamamen Katılıyorum) ifadeleri kullanılmıştır. Flow yaşantısı (ilk 10 madde) ve Kayg1 (son üç madde) boyutlarını içeren ölçeğin birbirini bütünleyen bir yapıya sahip olduğu kabul edilmektedir (Rheinberg, Vollmeyer ve Engeser, 2003). Orijinal ölçekte yer alan maddelerin aritmetik ortalama değerlerinin 4.18 ile 5.16 arasında değiştiği, standart sapma değerlerinin de .93 ile 1.32 arasında olduğu gözlenmiştir. Tüm maddeler için verilen yanıtlar 1 ile 7 arasındadır. Faktör analizi sonucunda öz değeri 1.00'den yüksek olan ve varyansın \%55'ini açılayan 2 faktörlü bir çözüme ulaşılmıştır. Flow yaşantısı ve kaygı alt ölçeklerinin Cronbach Alpha iç tutarlılık katsayıları .80 -.90. arasindadır. Rheinberg, Vollmeyer ve Engeser (2003) Flow Yaşantısı Ölçeği Kısa Formu ile elde edilmesi hedeflenen flow yaşantısı verilerinin ESM (Experience Sampling Method) yaşantı örnekleme yöntemi ile toplanmasını önermektedirler. ESM yöntemi, kişilerin aktivite esnasında yaşantılarına olabildiğince yaklaşabilmek amacıyla Csikszentmihalyi ve Larson (1987) tarafindan önerilmiştir. Bu yöntemin avantaj1, ölçümün aktiviteye kısa bir ara verilmesiyle yapılabilmesi ve aktivite yaşantısı ile ilgili geçerli ve güvenilir verinin uygun kısa formlu ölçekler vasıtasıyla kısa sürede toplanmasına olanak sağlamasıdır. Daha önce ESM yöntemi ile yapılan çalısmalarda, ölçeklerin uzunluğu, yöntemin uygulanmasını zorlaştırdığından uzun ölçekler için pek uygun olmadığı belirtilmektedir (Rheinberg, Vollmeyer ve Engeser, 2003; Rheinberg, 2004). Flow yaşantısı ölçeğinin kısa formu ile ESM yönteminin birleştirilmesi ile aktivitenin kısa süreliğine kesilmesi ile yapılan etkinliğin amaçlarına olumsuz bir etkisi olmamaktadır. Ölçeğin uygulanması ortalama 3-5 dakika aralığında sürmektedir ve hemen toplanıp, aktivite kaldığı yerden devam edebilmektedir. Ölçek, istenilen her alandaki aktivitelerde kişilerin flow yaşantısı deneyimlerini belirleyebilme özelliğine sahiptir. Bu bağlamda, orijinal ölçeğin geliştirilmesi sürecinde Engeser vd. (2005) tarafindan bir yabancı dil kursunun dil öğrenim ortamında yapılan araştırmada, flow yaşantısı ile başarı puanlanı arasındaki ilişkiye bakılmış ve sonuçta başarı notu ile flow yaşantısı arasında $(r=.49 ; \mathrm{p}<.01)$ orta düzeyde anlamlı ilişki saptanmıştır. Benzer şekilde Bischoff (2003) üniversite bünyesindeki yabancı dil derslerinde flow yaşantısı ile yabancı dil başarısı arasında .40 düzeyinde $(\mathrm{p}<.01)$ korelasyon değeri elde etmiştir. Engeser’in ( 2005) üniversite istatistik bölümünde okuyan öğrencilerle yaptı̆̆ı çalışmada, flow yaşantısının öğrencilerin yılsonu başarılarının \%5\%ini 
İşigüzel, B., \& Çam, S. (2014). Flow Yaşantısı Ölçeği Kısa Formunun Türkçeye uyarlama, geçerlik ve güvenirlik çalışmasi. International Journal of Human Sciences, 11(2), 788-801. doi: 10.14687/ijhs.v11i2.2826

açıkladığını saptamıştır. Wendland, Berger ve Rheinberg (2003) bilgisayar oyunları esnasında flow yaşatısı ile oyundaki başarı arasında (.35 ile .45 $(\mathrm{p}<.01)$ aralığında korelasyon değerleri olduğunu bulmuşlardır.

\section{Ölçeğin Çevirisi ve Denemelik Formun Oluşturulması}

Ölçeğin bu çalışmada kullanılabilmesi için, ölçek yazarlarının her birinden elektronik posta yoluyla izin alınmıştır. Orijinal ölçek üç dil uzmanı tarafindan ayrı ayrı Türkçeye çevrilmiş ve üç çeviri metni incelenerek çeviriler arasındaki farklar değerlendirilip, tek bir metin haline getirilmiştir. Ardından çevrilmiş Türkçe metin, Türkçeden kaynak dil Almancaya tekrar çevrilip özgün madde yapıları ile olan tutarlılıkları incelenmiştir. Bu inceleme sonucunda, orijinal ölçekteki maddeler ile Türkçeden yapılan çeviri ile elde edilen formdaki maddelerin dil denkliği sağladığı saptanmıştır. Ölçeğin çeviri geçerliği için çevrilen Türkçe formu İngilizce hazırlık sınıfında öğrenim gören 25 öğrenciye uygulanmıştır ve maddelerin anlaşılabilirlĭği açısından geri bildirim alınmıştır. Bu geribildirimler doğrultusunda çeviriyi yapan uzmanlar gerekli düzeltmeleri yaparak ölçek maddelerine son şeklini vermişlerdir. Böylece ölçme aracının Türkçe deneme formu uygulamaya hazır hale getirilmiştir.

\section{Verilerin Toplanması ve Analizi}

Veri toplama işlemi 2013-2014 öğretim y1lı güz döneminde grup halinde sinıf ortamında bu çalışmanın birinci yazarı tarafindan gerçekleştirilmiştir. Veri toplama zamanı önceden örneklemde yer alan öğrencilerin derslerine giren öğretim elamanlarıyla görüşülmüş ve veri toplama süreci planlaması yapılmıştır. Uygulamanın yapılacağı gruplarda veri toplama işleminin kararlaştırıldığı ders saatlerinde ESM yöntemine göre dersin 15. dakikasında araştırmacı derse girerek derse ara verilip öğrencilere çalışmanın amacı ve yönerge açılanarak uygulama yapılmıştır. Ölçeğin uygulaması toplam 3-5 dakika aralığında sürmüştür. Toplanan veriler SPSS 17.5 for Windows paket programıyla analiz edilmiştir. Analizlerde Açılkayıcı Faktör Analizi (principal axis factoring),basit doğrusal korelasyon, t - testi ve Cronbach Alfa teknikleri kullanılmışır. Faktör analizi sonucunda madde seçimi ve maddelerin hangi faktörde yer alacaklarına yönelik kararın verilmesinde şu iki ölçüt benimsenmiştir: Bir maddenin faktör yükü değerinin en az .40 olması ve birden çok faktöre yüklenen maddelerin iki faktör yükü arasındaki değer farkının .20 olmasıdır. İstatistiksel sonuçların yorumlanmasında anlamlılık düzeyi .05 olarak ölçüt alınmıştır. 
İşigüzel, B., \& Çam, S. (2014). Flow Yaşantısı Ölçeği Kısa Formunun Türkçeye uyarlama, geçerlik ve güvenirlik çalışması. International Journal of Human Sciences, 11(2), 788-801. doi: 10.14687/ijhs.v11i2.2826

\section{Bulgular}

Ölçeğin geçerlik çalışmasında yapı ve ölçüt bağıntılı geçerliği incelenmiş ve elde edilen bulgular aşağıda sunulmuştur.

\section{Yapı Geçerliği}

Ölçekte yer alan maddelerin betimsel değerlerine bakılmış aritmetik ortalama değerlerinin 3.59 ile 4.45 arasında değiştiği, standart sapma değerlerinin de 1.64 ile 2.30 arasında olduğu gözlenmiştir. Tüm maddeler için verilen yanıtlar 1 ile 7 arasındadır. Madde puanlarının çarpıklık değerlerine bakıldığında bu değerlerin .23 ile -.82 arasında değiştiği; basıklık-sivrilik katsayılarının ise -.31 ile -1.40 arasında olduğu gözlenmiştir. Ölçeğin faktör yapısını belirlemek için yapılan Açıklayıcı Faktör Analizinde (AFA) örneklem yeterlilik katsayısı (KMO) değerinin .88 olduğu $\left(\chi^{2}=1036.19 ; \mathrm{p}<.000\right)$ ve maddelerin ortak varyans değerlerinin de .26 ile .60 arasında değiştiği görülmüştür. Faktör analizi sonucunda öz değeri 1.00'den yüksek olan ve varyansın \%44.06'sını açılayan 2 faktörlü bir çözüme ulaşılmıştır. On maddenin toplandığ1 birinci faktörün öz değeri 5.00, açıkladığı varyans \%34.27 ve üç maddenin toplandığı ikinci faktörün öz değeri 1.79 ve açıladığı varyans ise \% 9.79'dur. Bu sonuçlara ve maddelerin faktör yükleriyle kümelenme durumlarına bakılarak analizlerde veri dönüştürme işlemine ihtiyaç duyulmamıştır.

Faktör analizi sonucunda elde edilen değerler ve her bir maddenin yer aldığı faktördeki maddelerin toplam puanıyla olan korelasyon değerleri Tablo 2'de verilmiştir.

Tablo 2. Maddelerin Faktör Yükü ve Madde- Alt Ölçek Korelasyon Değerleri

\begin{tabular}{|l|c|c|c|}
\hline \multicolumn{1}{|c|}{ Madde No } & Faktör I & Faktör II & r** \\
\hline madde8 & $\mathbf{, 7 6}$ &, 05 &, 70 \\
\hline madde9 & $\mathbf{, 7 4}$ &, 07 &, 69 \\
\hline madde6 & $\mathbf{, 7 0}$ &, 09 &, 66 \\
\hline madde2 & $\mathbf{, 7 0}$ &,- 03 &, 64 \\
\hline madde5 & $\mathbf{, 6 7}$ &, 00 &, 63 \\
\hline madde10 & $\mathbf{, 6 6}$ &, 09 &, 61 \\
\hline madde1 & $\mathbf{, 6 2}$ &,- 07 &, 57 \\
\hline madde7 & $\mathbf{6 0}$ &, 08 &, 56 \\
\hline madde3 & $\mathbf{, 5 5}$ &, 06 &, 53 \\
\hline madde4 & $\mathbf{5 0}$ &, 01 &, 48 \\
\hline madde13 &,- 12 & $\mathbf{7 7}$ &, 58 \\
\hline madde12 &, 08 & $\mathbf{6 0}$ &, 43 \\
\hline madde11 &,- 37 & $\mathbf{5 3}$ &, 43 \\
\hline Özdeğer & 5.00 & 1,79 & \\
\hline Aç1k.Varyans & 34,27 & 9,79 & \\
\hline Toplam & 34,27 & 44,06 & \\
\hline
\end{tabular}

** $\mathrm{p}<0.01$ 
İşigüzel, B., \& Çam, S. (2014). Flow Yaşantısı Ölçeği Kısa Formunun Türkçeye uyarlama, geçerlik ve güvenirlik çalışmasi. International Journal of Human Sciences, 11(2), 788-801. doi: 10.14687/ijhs.v11i2.2826

Tablo 2'de görüldüğü gibi flow yaşantısını ölçen 10 maddenin .50 ile .76 arasında değerlerle 1. Faktöre yüklendiği, kayg1 yaşantısını ölçen üç maddenin ise .53 ile .77 değerleri arasında 2. Faktörde toplandığ1 bulunmuştur. Maddelerin yüklendikleri faktörün toplam puanıyla olan ilişkilere bakıldığında flow yaşantısı olarak adlandırılan boyutta korelasyon değerlerinin .48 ile .70 arasında, kaygı yaşantısı olarak adlandırılan boyuttaki korelasyon değerlerinin ise .43 ile .56 arasında değiştiği gözlenmiştir. Flow yaşantısını ölçen 10 maddeden alınan puanlarla kaygı yaşantısını ölçen üç maddeden alınan puanlar arasında anlamlı düzeyde olmamakla birlikte beklenen yönde bir korelasyon değeri elde edilmiştir ( $r=-.12 ; \mathrm{p}>0.05)$. Madde puanlarının birbirleriyle ilişkilerine bakıldığında flow yaşantısını ölçen 10 madde için hesaplanan korelasyon değerlerinin .27 ile .60 arasında olumlu yönde olduğu bulunmuştur. Bu değerler kaygı yaşantısını ölçen maddeler için .27 ile .46 arasındadır.

\section{Ölçüt Bağıntılı Geçerlik}

Yapılan literatür taramasında flow yaşantısı ile cinsiyet arsındaki ilişkiye yönelik herhangi bir bilgiye rastlanmamıştır. Ancak bu duruma rağmen cinsiyete göre puan farklarının olup olmadığı incelenmiştir. Öğrencilerin ölçek puanlarının hem flow yaşantısı ( $t=1,636 ; p>.05)$, hem de kaygı puanlarının ( $\mathrm{t}=-, 850 ; \mathrm{p}>.05)$ cinsiyet değişkenine göre farklılaşmadığı sonucuna ulaşılmıştır. Yabancı dil öğrenme başarısının flow yaşantısıyla ilişkili olduğu yönündeki bilgiler doğrultusunda (Engeser vd., 2005; Bischoff, 2003) üniversite hazırlık sınıfındaki öğrencilerin, aracın alt ölçek ve toplam puanlarıly dönem sonu yabancı dil (Almanca) başarı puanları arasındaki ilişkilere bakılmışır $(\mathrm{N}=222)$. Sonuçta dönem sonu başarısının flow yaşantısı ile ( $\mathrm{r}=$ .21) ve kayg1 ile $(r=-.34)$ düşük düzeyde anlamlı ilişkiler göstermiştir $(\mathrm{p}<.01)$.

\section{Güvenirlik Çalışması}

Ölçeğin güvenirliği için 222 öğrenciden toplanan verilerle iç tutarlık katsayısı hesaplanarak bakılmıştır. Flow yaşantısı boyutu için Cronbach Alfa iç tutarlılık katsayısı .88, kaygı yaşantısı boyutu için .67 ve ölçeğin toplam puanı için iç tutarlık katsayısının .78 olduğu görülmüştür.

\section{Tartışma ve Sonuç}

Ölçeğin faktör yapısını belirlemek amacıyla yapılan AFA çalışması sonucunda, toplam 13 maddenin varyansın \%44.06'sını açıklayan ve öz değeri 1.00'den yüksek olan iki faktörde toplandığ1 görülmüştür. Sosyal bilimler için yapılan analizlerde çok boyutlu yapılar için varyansın \% 40 ile \% 60 arasında değişen varyans oranlarının faktör yapısı için yeterli kabul edilmektedir (Scherer, Wiebe, Luther ve Adams, 1988: akt. Tavşancıl, 2002). Çalışmada uyarlaması yapılan ölçek için elde edilen sonucun bu ölçütü karşıladığı görülmektedir. Ayrıca 
İşigüzel, B., \& Çam, S. (2014). Flow Yaşantısı Ölçeği Kısa Formunun Türkçeye uyarlama, geçerlik ve güvenirlik çalışmasi. International Journal of Human Sciences, 11(2), 788-801. doi: 10.14687/ijhs.v11i2.2826

maddelerin faktörlere yüklenme durumlarına bakıldığında ölçeğin orijinalinde belirtildiği gibi (Rheinberg, Vollmeyer ve Engeser, 2003) flow ve kayg1 yaşantısı faktörlerinde kümelendikleri saptanmıştır. Faktör analizine ilişkin bu sonuçlar uyarlanan ölçeğin Türk kültüründe de basit ve kararlı bir yapı gösterdiği şeklinde yorumlanabilir. Ayrıca maddelerin ilgili oldukları alt ölçek puanlarıyla olan ilişkilerinin de tatminkâr düzeyde olması ölçülmesi hedeflenen yapının homojenliğine işaret etmektedir. Literatürde teorik olarak ölçeğin flow ve kayg1 yaşantıs1 arasında negatif ilişki olduğu kabul edilmektedir. Bu çalısmada da anlamlı olmamakla birlikte negatif yönde bir ilişki gözlenmiştir.

Yabancı dil öğrenme başarısının flow yaşantısıyla ilişkili olacağı görüşü doğrultusunda üniversite hazırlık sınıfındaki öğrencilerin, ölçekten aldıkları puanalrla dönem sonu başarı puanları arasındaki ilişkilere bakılmıştır ve sonuçta beklendiği gibi flow için .21 ve kayg1 için .34 değerleri elde edilmiştir. Bu sonucun da başarı ve flow yaşantısı arasındaki ilişklerin incelendiği araştırma bulgularıya (Engeser, 2005; Engeser vd., 2005; Bischoff, 2003; Wendland, Berger ve Rheinberg, 2003)) tutarlı olduğu gözlenmektedir. Çalışmanın bu bulgusu uyarlanan ölçeğin ölçüt bağıntılı geçerliğine ilişkin önemli bir kanıttır. Cinsiye göre yapılan puan karşılaştırmasında her iki boyutta anlamlı fark gözlenmemiştir. Bu sonucun ölçeğin ölçüt geçerliği için sağlam bir dayanak olarak ele alınması oldukça sınırlıdır. Başak benzer çalışmalarda da puanların cinsiyet açısından karşılaştırılmasına gereksinim vardır.

Ölçeğin iç tutarlık güvenirlik katsayılarına bakıldığında Cronbach Alfa katsayları değerlerinin flow yaşantısı boyutu için .88, kaygı yaşantısı boyutu için .67 ve ölçeğin toplamı için .78 olduğu görülmüştür. Bir ölçeğin güvenirliğinin yüksek kabul edilmesi için genel olarak kabul edilen değerin .70 ve üstü olması yönündedir (Fink ve Kosakof, 1985; Anastasi, 1988: akt. Tavşancıl, 2002). Uyarlanan ölçek için elde edilen değerler toplam ölçek puanı ve flow boyutu için bu ölçütü karşılamakla birlikte, kayg1 yaşantısı için elde edilen 67 değeri bunun altında kalmaktadır. Ancak değerin .70'den çok düşük olmadığ1 ve bu boyutta sadece üç maddenin olması bu değerin kabul edilir olduğu şeklinde değerlendirilebilir.

Uyarlama çalışmasında elde edilen bulgulara bakılarak aracın 13 madde ile yabancı dil hazırlık sınıflarındaki üniversite öğrencilerinin yabancı dil öğrenme süreçlerinde flow yaşantılarını ölçmede kullanılabilecek psikometrik özelliklere sahip olduğunu göstermektedir.

Sonuç olarak, flow yaşantısı ölçeğinin Türk üniversite öğrencilerinin yabanc1 dil derslerindeki flow yaşantılarının ölçülmesinde kullanılabilir olduğu söylenebilir. Uygulamanın bir üniversitenin hazırlık sınıfı öğrencileri ile sınırlı tutulması, çalışmanın bir sınırlılığı olarak görülmektedir. Daha büyük örneklemler üzerinde yapılacak çalışmalarla ölçme aracının faktör yapısı ile ilgili farklı modellerin farklı analiz yöntemleri kullanılarak yeniden incelenmesinin de 
İşigüzel, B., \& Çam, S. (2014). Flow Yaşantısı Ölçeği Kısa Formunun Türkçeye uyarlama, geçerlik ve güvenirlik çalışması. International Journal of Human Sciences, 11(2), 788-801. doi: 10.14687/ijhs.v11i2.2826

yararlı olacağı düşünülmektedir. Ayrıca, ölçeğin kısa form haline getirilmiş olması uygulama kolaylı̆̆ı sağlamasının yanı sıra, katıllımcıların aktivite esnasındaki flow yaşantılarını da kısa sürede ölçülebilmesine olanak sağlamaktadır. Ölçeğin Türkçe formunun oluşturulmasının yabancı dil öğrencilerinin akademik başarılarını geliştirmeye yönelik çalışmalara bir başka boyut daha ekleyebileceği düşünülmektedir.

\section{Kaynakça}

Alperer, S. (2005). The Impact of Choice Provision on Students' Affective Engagement in Tasks: A Flow Analysis. MA Thesis. Bilkent University. Ankara: The Institute of Economics and Social Sciences..

Apelt, W., ve Krück, B. (1980). Motivationsproblematik im Fremdsprachenunterricht Kritische Bemerkungen zu "modernen" Motivationsinterpretationen. Deutsch als Fremdsprache,17 (1), 1-12.

Bischoff, J. (2003). Lernmotivation, Flow- Erleben und Leistung in universitären Fremdsprachenkursen. Unveröffentliche Diplomarbeit, Institut für Psychologie der Universität Postdam.

Csikszentmihalyi, M. (1975). Beyond boredom and anxiety. San Francisco: Jossey-Bass Publishers.

Csikszentmihalyi, M., ve Larson, R. (1987). Validity and reliability of the Experience Sampling

Method. Journal of Nervous and Mental Disease, 175, 529-536.

Csikszentmihalyi, M. (1988). The future of flow. In M. Csikszentmihalyi ve I. Csikszentmihalyi (Eds.), Optimal experience: Psychological studies of flow in consciousness (pp. 364-383). New York: Cambridge University Press.

Csikszentmihalyi, M. (1990). Flow: The psychology of optimal experience. New York: Harper \& Row.

Csikszentmihalyi, M., ve Csikszentmihalyi, I., Hrsg. (1991). Die außergewöhnliche Erfahrung im Alltag. Die Psychologie des Flow-Erlebnisses. Stuttgart: Klett-Cotta.

Deci, E. (1975), Intrinsic motivation, New York: Plenum Press.

Deci, E. L., ve Ryan, R. M. (1985). Intrinsic motivation and self-determination in human behavior. London: Plenum Press.

Egbert, J. (2003). The study of flow theory in the foreign language classroom. The Modern Language Journal, 87, 499-518.

Engeser, S. (2005). Lernmotivation und volitionale Handlungssteuerung: Eine Längschnittuntersuchung beim Statistiklernen im Psychologiestudium. Dissertation. Institut für Psychologie der Universität Postdam.

Engeser, S., Rheinberg, F., Vollmeyer, R., ve Bischoff, J. (2005). Motivation, Flow-Erleben und Lernleistung in universitären Lernsettings. Zeitschrift für Pädagogische Psychologie, 19 , 159-172.

Engeser, S. ve Rheinberg, F. (2008). Flow, moderators of challenge-skill-balance and performance. Motivation and Emotion, 32, 158-172.

Engeser, S. ve Schiepe-Tiska, A. (2012). Historical lines and overview of current research. In S. Engeser (Hrsg.), Introduction to flow research. New York: Springer. 
İşigüzel, B., \& Çam, S. (2014). Flow Yaşantısı Ölçeği Kısa Formunun Türkçeye uyarlama, geçerlik ve güvenirlik çalışmasi. International Journal of Human Sciences, 11(2), 788-801. doi: 10.14687/ijhs.v11i2.2826

Fraser, B. J. ve Walberg, H. J. (Eds.) (1991). Educational Environments. New York: Pergamon.

Kleppin, K. (2001). Motivation, Nur ein Mythos? (I). Deutsch als Fremdsprache, 38, 219-225.

Loehr, J. E. (1986). Mental toughness training for sports: Achieving athletic excellence. New York: Plume.

Martin, J. $\quad$ P. (2000). Lernen durch Lebren: ein modernes Unterrichtskonzept. In: Schulverwaltung Bayern: Link Verlag, 1-13.

Rathunde, K. (2003), A Comparison of Montessori and Traditional Middle Schools: Motivation, Quality of Experience, and Social Context. The NAMTA Journal. 28 (3), 13-52.

Rheinberg, F., Vollmeyer, R., ve Rollett, W., (2000). Motivation and action in self-regulated learning. In M. Boekaerts, P. Pintrich, ve M. Zeidner (Eds.), Handbook of selfregulation (pp. 503-529). San Diego: Academic Press.

Rheinberg, F. ve Vollmeyer, R. (2001). Flow- Erleben: Untersuchungen zu einem populären, aber untersperifizierten Konstrukt. DFG Forschungsantrag. Universität Postdam: Institut für Psychologie.

Rheinberg, F. (2002). Freude am Kompetenzerwerb, Flow-Erleben und motivpassende Ziele. In M. von Salisch (Ed.), Emotionale Kompetenz entwickeln. Grundlagen in Kindheit und Jugend (pp. 179-206). Stuttgart: Kohlhammer.

Rheinberg, F., Vollmeyer, R., ve Engeser, S. (2003). Die Erfassung des Flow-Erlebens [The assessment of flow experience]. In J. Stiensmeier-Pelster \& F. Rheinberg (Eds.), Diagnostik von Motivation und Selbstkonzept (pp. 261-279). Göttingen: Hogrefe.

Rheinberg, F. (2004). Motivationsdiagnostik. Göttingen. Hogrefe Verlag.

Rheinberg, F. (2008). Intrinsic motivation and flow-experience, In Motivation and action (Heckhausen, J. and Heckhausen, H. Eds.), Cambridge University Press, Cambridge, 323-348.

Rossin, D. Ro, Y.K., Klein, B.D. \& Guo, M. (2009). The Effects of Flow on Learning Outcomes in an Online Information Management Course. Journal of Information Systems Education. West Lafayette: Spring 2009. Vol. 20, 1; 87-99.

Shernoff, D. J., Csikszentmihalyi, M., Schneider, B., ve Shernoff, E. S., (2003). Student engagement in high school classrooms from the perspective of flow theory. School Psychology Quarterly, 18, 158-176.

Tardy, C. M. ve Snyder, B. (2004). That's why I do it: Flow and EFL teachers' practices. English Language Teachers Journal, 58(2), 118-128.

Tavşancıl, E. (2002) . Tutumların ölçülmesi ve SPSS ile veri analizi, Ankara: Nobel Yayınları.

Vollmeyer, R., ve Rheinberg, F. (1998). Motivationale Einflüsse auf Erwerb und Anwendung von Wissen in einem computersimullerten System. Zeitschrift für Pädagogische Psychologie, $12,11-23$.

Webster, J. , Trevino, L., ve Ryan, L. (1993). The dimensionality and correlates of flow in human- computer interactions. Computer in Human Behaviour, 9, 411-426.

Wendland, M., Berger, A. and Rheinberg, F. (2003). Flow-Erleben und Leistung in einem Onlinespiel. In Experimentelle Psychologie. 45. Tagung experimentell arbeitender Psychologen, 228, Pabst, Lengerich. 
İşigüzel, B., \& Çam, S. (2014). Flow Yaşantısı Ölçeği Kısa Formunun Türkçeye uyarlama, geçerlik ve güvenirlik çalışmasi. International Journal of Human Sciences, 11(2), 788-801. doi: 10.14687/ijhs.v11i2.2826

\section{Extended English Abstract}

Since the beginning of the flow research by Csikszentmihalyi (1975; 1990), who was interested in finding why or how some people become engrossed in doing what they do, it has been expected that flow is related to performance, and several studies have indeed reported this relationship. The flow state is an optimal state influenced by one's intrinsic motivation, where the person is fully immersed in what he or she is doing. Csikszentmihalyi conducted in his interviews with people who performed activities that do not directly lead to extrinsic rewards (Csikszentmihalyi and Csikszentmihalyi, 1988) and the intrinsically rewarding experience leads people to higher levels of performance (Csikszentmihalyi, 1990). Flow describes the state of self reflection- free immersion in a continual activity that one still has under control in spite of high stress levels (Rheinberg, 2008). Time and place, as well as an original external aim of the activity that has been present, are forgotten and the individual is totally absorbed by the activity (Csikszentmihalyi, 1975; Rheinberg and Vollmeyer, 2003). The six components of the flow experience are; (1) A balance between perception of one's skills and the perception of difficulty of the activity (task demand). In this state of balance, one feels both optimally challenged and confident that everything is under control. (2) The activity has coherence, contains no contradictory demands, and provides clear, unambiguous feedback. (3) The activity seems to be guided by an inner logic. (4) A high degree of concentration on the activity due to undivided attention to a limited stimulus field. (5) A change in one's experience of time. (6) The self and the activity are not separated, leading to a merging of the self and the activity and the loss of self-consciousness (Csikszentmihalyi, 1975; Rheinberg, 2008; Rheinberg and Engeser, 2008; Engeser and Schiepe-Tiska, 2012). Many studies have established the positive relationship between flow and improved learning in young adults (Rathunde, 2003) and high school students (Shernoff et al. 2003). Research has found relations between flow and students' perceived learning of the subject matter, students' perceived skill development, and student satisfaction (Rossin et al. 2009). Recent years have seen a steady interest about flow experience in the foreign language classroom (Egbert, 2003; Alperer, 2005; Trady and Snyder, 2004; Engeser et al. 2005; Bischoff, 2003). The purpose of this study was to adapt the Flow Short Scale into Turkish, which was developed by Rheinberg, Vollmeyer and Engeser (2003) for German society. The Flow Short Scale has been validated in various applications ranging from experimental studies. Flow Short Scale measures proved to be a performance predictor of statistical education (Engeser et al., 2005), computer games (Rheinberg and Vollmeyer, 2003; Vollmeyer and Rheinberg, 2003; Wendland et al., 2003), the inbox task (Rheinberg et al., 2003) and the experience sampling method (Rheinberg et al., 2007). The original scale includes two sub- dimensions which are called; Flow (10 items) and Anxiety (3 items). The scale consists 13 items constructed in a form of 7 - point Likert Scale $(1=$ completely disagree, $7=$ completely agree). The research sample includes 222 university prep class students, 124 females; 98 males and aged between 17-24. To satisfy the translation equivalence, the scale was translated by 3 Turkish- German language specialists into Turkish and translated back to German again. The Turkish form was applied to a small university prep class student sample (N:25) who assessed the items in respect of clarity. After the translation process, necessary expression changes were done in direction of the specialists' opinions. The factor structure of the scale was investigated by exploratory factor analysis (EFA). The Kaiser Mayer Olkin value of the scale is .88 and Bartlett test of meaningfulness value is $\mathrm{X}^{2}=1036.19 ; \mathrm{p}<.000$. The results of the analysis showed that the factor structures of the scale, which has two complementary sub- scales (flow- anxiety), were similar with the original scale. This analysis resulted in the scale with a factor accounted for $44.06 \%$ of total variance with 13 items. Factor loadings of Flow Short Scale ranged from .50 to .77 . Cronbach's Alpha internal consistency test for the 
İşigüzel, B., \& Çam, S. (2014). Flow Yaşantısı Ölçeği Kısa Formunun Türkçeye uyarlama, geçerlik ve güvenirlik çalışmasi. International Journal of Human Sciences, 11(2), 788-801. doi: 10.14687/ijhs.v11i2.2826

sub- dimension Flow was (.88) and for Anxiety (.67). The overall reliability of the scale was high (.96). The exploratory factor analysis was conducted to identify the sub-factors of the original 13 items and 2 sub- classes were found. There was no differences between the original scales' factors and the current studies' sub-factors by the adaption for the Turkish society. The variance explained by the overall scale was $44.06 \%$; the sub- dimensions Flow $34.27 \%$ and by the Anxiety $9.79 \%$. The foreign language achievement final points of the semester were used for the criterion validity. There was $r=.21$ correlation between flow experience and the language achievement final points and $\mathrm{r}=.34$ correlation between anxiety and the language achievement final points $(\mathrm{p}<.01)$. The findings revealed that the Flow Short Scale was a reliable and valid instrument for measuring university students' flow experiences by the foreign language lessons in prep- classes. 